\title{
Discursos silenciosos, discursos silenciados. Lá apropiación enunciativa como operación discursiva
}

Gabriel Dvoskin ${ }^{1}$

Resumen: En este artículo, nos proponemos aportar al estudio de los mecanismos que regulan la configuración del sentido de un texto. Para ello, adoptamos una perspectiva discursiva (Pêcheux, 1975; Verón, 1986), enfoque que implica tomar distancia de aquellas teorías que han identificado este fenómeno con el reflejo de las intenciones del sujeto hablante (Austin, 1962; Grice, 1957; Searle, 1969). En su lugar, focalizamos nuestra atención en el enunciado en tanto eslabón de la cadena discursiva (Voloshinov, 1929): es el universo de lo decible lo que otorga valor a los signos, por lo que es la modalidad de funcionamiento de la red discursiva lo que nos proponemos analizar, no sólo para identificar y entender por qué predominan ciertos signos y sentidos en nuestra sociedad; también nos interesa indagar qué otros sentidos son posibles. Sostenemos que estos fenómenos pueden ser explicados mediante las relaciones de fuerza que mantienen las distintas formaciones discursivas que integran la red, característica que se manifiesta al interior del texto, y que funciona como un mecanismo discursivo que configura el sentido a partir de regular las interpretaciones posibles $y$ excluir las no posibles. A su vez, nos atrevemos a afirmar que son estos mismos mecanismos los que abren la posibilidad a que nuevos signos circulen y a que nuevas valoraciones se impongan.

Palabras clave: discurso; sentido; escena discursiva; apropiación enunciativa.

Resumo: Propusemos abordar, neste artigo, um estudo dos mecanismos que regulam a configuração do sentido de um texto. Para tanto, adotamos uma perspectiva discursiva (Pêcheux, 1975, Verón, 1976), enfoque que implica tomar distância das teorias que identificam este fenômeno com o reflexo das intenções do sujeito falante (Austin, 1962, Grice, 1957, Searle, 1969). Em seu lugar, focalizamos nossa atenção no enunciado como um elo da cadeia discursiva (Voloshinov, 1929); é o universo do dizível o que outorga valor aos signos. O que nos propomos a analisar, é a modalidade de funcionamento da rede discursiva, não somente para identificar e entender porque predominam certos signos e sentidos em nossa sociedade, mas também questionar que outros sentidos são possíveis. Sustentamos que estes fenômenos podem ser explicados mediante as relações de força que as formações discursivas distintas, integrantes da rede, mantêm; característica que se manifesta no interior do texto e que funciona como um mecanismo discursivo, configurando o sentido ao regular as interpretações possíveis e excluir as não-possíveis. Nos atrevemos, por este viés, a afirmar que são estes mesmos mecanismos os que abrem a possibilidade para que circulem novos signos e para que se imponham novas valorações.

Palavras-chave: discurso; sentido; cena discursiva; apropriação enunciativa.

1 Pesquisador del CONICET - Buenos Aires. 
La idea de que el uso del lenguaje está fundamentalmente asociado con la transmisión de informaciones de un sujeto a otro parecería ser una creencia tan fuertemente arraigada en el sentido común que tratar, en el ámbito cotidiano, la actividad lingüística como un hecho separado de un acto de entendimiento entre, por lo menos, dos personas se presenta como un desafío sumamente complejo. Esta perspectiva se sustenta en dos premisas íntimamente relacionadas entre sí, que postulan, por un lado, la asimilación del uso del lenguaje con una mera función referencial y, por el otro, la reducción de la comunicación a un fenómeno de mutua comprensión ${ }^{2}$.

Los fundamentos teóricos de esta relación entre lenguaje y comunicación tienen sus orígenes, paradójicamente, en una omisión: preocupado por establecer la autonomía de su objeto de estudio, Saussure (1916) excluyó al sujeto del campo de la lingüística y con él, dejó de lado toda preocupación por la comunicación ${ }^{3}$, operación a partir de la cual definió la lengua como un sistema de signos arbitrarios, relacionados entre sí de forma opositiva, que nada tienen que ver con la realidad extralingüística (Benveniste, 1966).

Esta omisión fue interpretada años más tarde por el Círculo de Praga como una obviedad, corriente que leyó el Curso de Lingüística General desde un enfoque instrumental (Verón, 1986). De acuerdo con esta escuela, el sistema de reglas y el conjunto finito de elementos que conforma la lengua constituyen un código, cuya esencia radica en funcionar como un medio para transmitir informaciones. La comunicación consistiría, desde esta perspectiva, en un proceso intencional de codificación por parte del emisor, quien trasmite su mensaje a un receptor, quien, por su parte, decodifica este mensaje y, de ese modo, reconoce la intención inicial del hablante (Ducrot, 1968). Este enfoque instrumental encuentra su cristalización en el sentido común con el refrán "hablando se entiende la gente", expresión que hace aparecer a la lengua como condición suficiente para la mutua comprensión entre dos personas.

Este modelo de la comunicación presenta a los interlocutores como espejos, diferenciados únicamente por el rol comunicativo que cumplen en la interacción. La noción de código atribuye a la lengua un carácter homogéneo y democrático, disponible para todos los miembros de la comunidad por igual. Quedan, así, desestimadas las diferencias en el acceso a los distintos roles sociales que desempeñan las personas cotidianamente, que establecen usos diferenciales de las formas lingüísticas y, por consiguiente, una distribución desigual de los significados, independientemente de cuál sea su competencia gramatical (Bourdieu, 1982; Lavandera, 1984). Por otro lado, este modelo de la comunicación supone una circulación lineal del sentido al postular una correspondencia unívoca entre la intención del emisor al producir su mensaje y el reconocimiento de su receptor al interpretarlo, fenómeno que otorga al lenguaje una transparencia que lo muestra como un simple reflejo del mundo ${ }^{4}$.

Entender la lengua como un código hace recaer las responsabilidades de la significación en los sujetos individuales. El éxito o fracaso de la comunicación reposa, siguiendo esta línea, en las voluntades del hablante para hacerse entender o bien en las aptitudes

2 De hecho, en la actualidad, en los libros de texto escolares de mayor circulación en la Argentina (Vasallo, 2011; Kaufman et al, 2017), predomina el "enfoque comunicativo" para abordar las temáticas relacionadas con el lenguaje, perspectiva que se sustenta en el circuito de la comunicación propuesto por Jakobson (1958).

3 Este desinterés por el aspecto comunicativo del lenguaje fue ratificado años más tarde por la gramática generativa (Chomsky, 1957), otra de las corrientes lingüísticas más influyentes del siglo XX.

4 Para una crítica más detallada de este modelo de la comunicación, véase Pêcheux (1969) y Kerbrat-Orecchioni (1980). 
del oyente para comprender "qué quiso decir" el emisor. Circunscribir el campo de la lingüística a las reglas inmanentes del sistema limita el alcance de los estudios sobre el uso del lenguaje, fundamentalmente lo concerniente al análisis del sentido, debido a que oculta las dimensiones histórica, política, social e ideológica que operan en su constitución.

En este artículo, nos proponemos aportar al estudio de los mecanismos que regulan, precisamente, la configuración del sentido de un texto, entendido este último como la unidad empírica que remite a una pieza lingüística concreta, emitida por un hablante o escritor en una situación histórica determinada (Pêcheux, 1975). Como ha señalado Verón, el análisis del sentido nos obliga a abandonar un enfoque centrado en el sujeto individual y nos exige posicionarnos en una perspectiva discursiva: "'Racionalidad' e 'irracionalidad' son propiedades predicables de los sujetos individuales. Las redes discursivas en la historia no son racionales ni irracionales: tienen modalidades de funcionamiento que hay que identificar y comprender" (Verón, [1986] 2007: 82). Es esta modalidad de funcionamiento de las redes discursivas lo que nos proponemos analizar, no sólo para identificar y entender por qué predominan ciertos signos y sentidos en nuestra sociedad; también nos interesa estudiar este funcionamiento para indagar qué otros sentidos son posibles y qué caminos es necesario emprender para construir otras realidades sociales a partir de imponer estos otros sentidos: marginales, prohibidos o sencillamente, aún inverosímiles.

\section{Tras las huellas de la red discursiva}

Adoptar un enfoque discursivo para los estudios sobre el sentido implica tomar distancia de aquellas teorías que han identificado este fenómeno con el reflejo de las intenciones del sujeto hablante. Podemos ubicar a la pragmática de origen anglosajón (Austin, 1962; Grice, 1957; Searle, 1969) entre estas corrientes, que si bien considera la dimensión constitutiva del uso del lenguaje, concibe el sentido de un enunciado como el resultado de las estrategias llevadas a cabo por un sujeto racional, consciente, amo de sus palabras (García Negroni et al, 2013). Por el contrario, posicionarnos en una perspectiva discursiva nos exige dejar de lado las voluntades e intenciones del sujeto empírico al momento de producir una emisión y focalizar nuestra atención, en su lugar, en el enunciado en tanto eslabón de la cadena discursiva (Voloshinov, 1929), esto es, en el modo en que un texto se inserta en la red discursiva. Es el universo de lo decible, el conjunto de discursos que circula socialmente, lo que otorga valor a los signos y expresiones que aparecen en el texto aislado, por lo que es esta relación la que debemos analizar y problematizar.

Esta red de discursos no es homogénea, sino que, como ha sostenido Pêcheux (1975), está organizada en regiones que conforman formaciones discursivas, cada una de ellas caracterizada por habilitar determinados signos y valoraciones y clausurar otros, funcionando, de este modo, como reglas sobre lo que puede y debe ser dicho. Las formaciones discursivas son propias de una formación social determinada, por lo que están en constante movimiento y tensión: sus límites están dados por el resto de las formaciones discursivas, con las que mantienen distintos tipos de relaciones (competencia, rechazo, apoyo, complementariedad, etc.). En esos límites, encontramos porosidad, permeabilidad; hay un exterior que es intrínsecamente constitutivo de la formación discursiva.

De acuerdo con Pêcheux, el individuo, interpelado por la ideología, se inscribe en una (o varias) formación(es) discursiva(s), que determinan posición(es) de sujeto que otorga(n) sentido a sus enunciados al establecer su relación con la memoria discursiva, esto es, con los enunciados ya formulados o posibles para esa(s) formación(es) discursiva(s). 
Se trata, entonces, de un sujeto histórico, descentrado, constituido desde el exterior por la ideología a partir de las voces ajenas que penetran en su propio texto, que se inmiscuyen de forma explícita, mediante la inclusión de posturas que no asume como propias y frente a las cuales adopta actitudes que oscilan entre el acuerdo o el rechazo; o bien, estas voces atraviesan al sujeto de forma más sigilosa, ya sea en los signos que recupera para abordar un determinado tema, ya sea en los acentos valorativos que cargan dichos signos.

Más allá de los diferentes grados de sutileza, el texto se presenta como un espacio intrínsecamente heterogéneo, habitado por diferentes voces y atravesado por diferentes formaciones discursivas. El sentido escapa, en consecuencia, al control del hablante, quien no tiene garantía alguna de que sus intenciones se correspondan con las interpretaciones que sus oyentes atribuyan a sus enunciados, independientemente de los esfuerzos que realicen ambos por entender(se). Sin embargo, esta incertidumbre no equivale a que haya tantas interpretaciones como interlocutores: nuevamente recurrimos a Verón para recordar que un enunciado produce un "campo de efectos posibles" (Verón y Sigal, [1985] 2008: 18). Esta característica no debe ser atribuida a la ambigüedad en la expresión de un hablante particular, sino que constituye una propiedad inherente al funcionamiento discursivo, a la que Verón y Sigal denominaron "el principio de la indeterminación relativa del sentido" ([1985] 2008: 18). Este principio presenta dos caras: por un lado, establece que la interpretación posible para un enunciado particular nunca es una sola; $y$, por el otro, postula que no cualquier interpretación puede ser evocada ante un determinado enunciado, sino que estas posibilidades están restringidas a un número limitado.

Verón ha propuesto estudiar este campo de efectos posibles mediante el análisis de las relaciones que el texto mantiene con sus condiciones históricas, ya sean estas las del momento de su producción como de su recepción, conjuntos de restricciones a los que ha denominado, respectivamente, "ideológico" y "poder" ([1986] 2007: 134). Sin embargo, esta distinción entre una gramática de producción y otra de reconocimiento resulta contradictoria en el marco de una teoría que propone estudiar el sentido desde un enfoque discursivo. Como el mismo Verón ha señalado, la distancia que existe entre la instancia de producción y la de reconocimiento es irrelevante para los participantes de la interacción; sólo resulta pertinente para el análisis que realiza el observador-investigador, quien se posiciona en un lugar diferente, "juega a otro juego", siguiendo el concepto de Wittgenstein: "El desfasaje entre producción y reconocimiento es un principio del observador y no del actor: es desde la posición de observador que se constata que ninguna 'comunicación', ningún intercambio de palabra, es 'transparente."” (Verón [1986] 2007: 194).

Toda producción discursiva es, en definitiva, la materialización de un reconocimiento, en tanto el texto -parafraseando a Bajtín y a Voloshinov- dialoga con otros discursos: previos, a los que recupera para apoyarse o criticar; o posibles, a los que configura como eventuales réplicas futuras. El fenómeno del sentido se plantea entonces como el análisis de cómo se posiciona el texto en la red discursiva, cómo configura su lugar entre los diferentes discursos con los que se relaciona y que le imprimen sus huellas, ya sea en la forma de condiciones de posibilidad para su producción, ya sea como sus posibles interpretaciones futuras. De este modo, el investigador siempre adopta la perspectiva del reconocimiento debido a que sólo desde esa posición puede dar cuenta de la distancia en relación con la producción, distancia necesaria para reconstruir aquellas huellas que otros discursos (pasados o posibles) han dejado en el texto.

Un análisis desde la perspectiva de la producción, tal como lo planteó Verón, que tiene como objetivo establecer el campo de efectos posibles de un texto, esto es, aventurar 
hipótesis sobre cuáles pueden ser las interpretaciones que reciba, no es otra cosa que el análisis del reconocimiento de las huellas que esos posibles futuros discursos han dejado en el texto. La distinción entre ambas instancias puede servir para dar cuenta de los diferentes roles comunicativos involucrados en la interacción, pero no hace ningún aporte al análisis del sentido de un texto dado que este fenómeno remite siempre a la instancia de reconocimiento.

Con el objetivo de delimitar ese campo de efectos posibles que genera un texto, Raiter retomó el principio de la indeterminación relativa del sentido y propuso el concepto de discurso dominante:

El discurso dominante, al quedar definido como un sistema de referencias social e inconscientemente aceptado, funciona como mecanismo de regulación de la circulación de significados posibles, es decir, funciona como límite y apertura de las posibles interpretaciones que pueden realizarse a partir de textos-estímulos (1999: 152).

El discurso dominante está constituido por los signos que mayor circulación tienen en la red y por los valores más difundidos de esos signos, más aceptados, y es a partir de él que se califica, se otorga valor al resto de los signos y discursos que conforma la red. De esta manera, un determinado enunciado será comprendido, según Raiter, en función de la distancia que mantenga respecto del discurso dominante. Ello genera que no sea necesario excluir o censurar determinados enunciados, sino que estos ya estarán valorados previamente (como verdaderos, falsos, marginales, humorísticos, absurdos, etc.) por su referencia al discurso dominante, que restringe la variedad de interpretaciones posibles -su campo de efectos de sentido- y, paralelamente, establece qué interpretaciones no son posibles en un momento histórico determinado.

Desde este enfoque, hay una referencialidad preexistente a todo texto individual, que establece no sólo los valores de los signos que en él aparecen, sino que también legitima qué temas puede abordar, qué puede ser motivo de debate, cuáles son los temas tabú, qué puede ser dicho y quién puede hacerlo. Esta iniciativa discursiva le otorga al discurso dominante el poder de contener (los temas, los signos, los valores), mientras que los otros discursos se limitarán a responder: más allá de que lo nieguen, rechacen o critiquen, se constituirán como discursos opositores del discurso dominante, por lo que quedarán integrados en él, confirmándolo y reforzándolo.

Un discurso que pretenda salir de ese lugar meramente contestatario debe constituirse como discurso opositor al discurso dominante: cuestionar su eje de referencias, criticar los valores impuestos por él e imponer nuevos signos y tópicos de discusión. Sólo así el discurso dominante no podrá calificarlo y se verá obligado a responderle, hecho que le hará perder la iniciativa discursiva. Un discurso que lograra ese tipo de relación constituiría un discurso emergente (Raiter, 2003), definido como aquel que cambia las referencias existentes y conforma entonces un nuevo discurso dominante.

Tanto la red discursiva como el discurso dominante son una abstracción, una (re) construcción, a las que sólo puede accederse mediante un trabajo crítico de análisis. Es a partir de la referencia a la red y de establecer el discurso dominante que el analista podrá conjeturar cuáles son las lecturas posibles para un determinado texto -su campo de efectos posibles, en términos de Verón- y, a su vez -retomando a Raiter (1999a)- qué otras interpretaciones no son posibles.

La noción de discurso dominante resulta sumamente productiva para explicar por qué, en un determinado momento histórico, se imponen ciertas interpretaciones por sobre 
otras en la lectura de un texto específico. Sin embargo, como decíamos unas líneas más arriba, el discurso dominante es una abstracción, una elaboración del analista, por lo que se corre el riesgo de caer en un análisis circular al justificar las interpretaciones posibles y las no posibles por las referencias a un eje definido de antemano por el investigador, que es previo al texto a analizar. Por otro lado, aún resta explicar por qué en ciertas interacciones tienen mayor preeminencia determinados signos y valoraciones, mientras que, en otras, resultan ser otros los más legitimados.

Sostenemos -y es lo que nos proponemos demostrar en este artículo- que estos fenómenos pueden ser explicados mediante las relaciones de fuerza que mantienen las distintas formaciones discursivas que integran la red, característica que se manifiesta al interior del texto, y que funcionan como un mecanismo discursivo que configura el sentido a partir de regular las interpretaciones posibles y excluir las no posibles. A su vez, nos atrevemos a afirmar que son estos mismos mecanismos los que abren la posibilidad a que nuevos signos circulen y a que nuevas valoraciones se impongan.

Nos interesa, por lo tanto, aportar a las teorías sobre el funcionamiento discursivo, a las que consideramos aún insuficientes y/o incompletas, y proporcionar un método de análisis que permita dar cuenta de las huellas de la red discursiva en los textos y de cómo esta opera en la configuración de su sentido.

\section{Acerca de la escena discursiva}

La necesidad de considerar la red discursiva para establecer los efectos de sentido posibles de un texto pone de relieve el carácter eminentemente dialógico y polifónico que atraviesa a todo uso del lenguaje (Bajtin, 1982; Voloshinov, 1929). Utilizamos el término "escena discursiva" (Dvoskin, 2015a) para hacer referencia a la configuración de voces y posicionamientos discursivos que se desarrollan en un texto particular, entre los que se incluyen los de quien enuncia y los de su(s) destinatario(s). Tomamos de Ducrot (1984) su metáfora teatral para ilustrar el uso del lenguaje, que presenta al locutor de un texto como el autor de una obra - entendidos ambos como sujetos discursivos -, quien pone en escena diferentes personajes, distintos enunciadores, cada uno de ellos evocando un punto de vista particular, un determinado topos. Del mismo modo que el autor de la obra no se expresa directamente ante su público sino a través del diálogo que establece entre los distintos personajes, el locutor se manifiesta a partir de la confrontación de las voces que trae a escena en su texto y de los diferentes posicionamientos que asume frente a cada uno de estos enunciadores: acercándose a sus posturas o distanciándose de ellas.

Sin embargo, nos alejamos de la propuesta de Ducrot al concebir a cada una de estas voces no sólo como una determinada opinión, sino como parte integrante de todo un discurso, atravesado por las diferentes formaciones discursivas que lo afectan. De este modo, la inclusión de un enunciador trae a escena todo un universo semántico, con sus propias restricciones y formas tópicas que subyacen, de manera más o menos explícita, a los encadenamientos argumentativos que desarrollan su punto de vista particular. De acuerdo con este enfoque, no es en la lengua donde se encontrarían los topoi convocados en la argumentación, como han postulado Ducrot y Anscombre (1988), sino en la red discursiva, esto es, es la configuración específica de fuerzas entre las distintas formaciones discursivas que atraviesan un texto lo que trae a escena determinados topoi y no otros, al habilitar la aparición de ciertos discursos y clausurar otros (Guimarães, 1998).

De esta manera, por ejemplo, si tomamos de forma aislada la expresión "yo nunca me drogué", seguramente lo primero que se active sea su encadenamiento con frases del tipo 
"tengo una conducta intachable", "soy una persona muy responsable", "soy confiable", etc., que valoran el signo [droga] de forma negativa y, por lo tanto, la misma calificación le corresponde a quien las consume, por lo que su negación presenta la forma tópica conversa. Sin embargo, esta orientación argumentativa - y aquí es donde nos alejamos del planteo de Ducrot y Anscombre- no está dada por algún elemento o valor léxico inscripto en el sistema de la lengua, sino por la posición de sujeto desde donde enuncia quien emite esa frase. Si esta es la orientación argumentativa que más fácilmente se activa si no explicitamos quién dijo esa frase, a quién se la dijo, en qué lugar, en relación con qué tema de conversación, es porque en la Argentina, en la actualidad del año 2017, los valores más difundidos del signo [droga] son [+perjudicial para la salud], [-prescripta por el médico] $\mathrm{y}$, principalmente, [+prohibida], razón por la cual quedan excluidas de esta categoría, por ejemplo, las aspirinas o el ibuprofeno y entran aquellas que desafían los discursos de la medicina y el derecho, de gran prestigio y legitimidad en nuestra sociedad.

Por otro lado, propusimos un ejercicio imposible de realizar: no se puede tomar una expresión de forma aislada, sino que siempre, inevitablemente, necesitamos reponer un contexto para su interpretación. Así, ante el enunciado "yo nunca me drogué", atribuimos su formulación, por ejemplo, a un aspirante en una entrevista laboral, a un adolescente que es interrogado por sus padres o a un político en campaña, todas posiciones que confirman las valoraciones más difundidas y aceptadas del signo [droga] y, por lo tanto, las que se activan con mayor facilidad.

Sin embargo, distinto sería el caso si la frase en cuestión fuera pronunciada por una persona que está internada en un hospital, listando las actividades que se arrepiente de no haber experimentado. En esta situación, lo que cobra mayor relevancia no es el carácter dañino o prohibitivo que se le adjudica al signo [droga] desde el discurso médico o judicial, sino que se presentan con mayor énfasis aquellos otros discursos, menos difundidos, más desprestigiados, que destacan los aspectos positivos de las drogas, como, por ejemplo, aquellos que las vinculan con la mayor sensibilidad, la desinhibición o el placer ${ }^{5}$.

El término "escena discursiva" resulta, así, más apropiado que el de escena enunciativa (Benveniste, 1966), dado que lo que se configura en el texto es la relación entre diferentes discursos, no sólo entre enunciadores, cada uno dominado por formaciones discursivas particulares, las cuales movilizan memorias discursivas específicas. Un texto resulta, entonces, un espacio inherentemente heterogéneo al estar atravesado por diferentes formaciones discursivas, cada una de las cuales trae a escena determinados discursos, con sus signos y valoraciones específicos, que pueden ser más o menos compartidos con otras. Es esta memoria discursiva particular la que regula -determina, retomando las palabras de Pêcheux (1975)- lo que puede y debe ser dicho y-agregamos nosotros- lo que no puede ser dicho por estar fuera de los límites de lo posible ${ }^{6}$ :

En un marco interaccional dado, los sentidos 'no literales' transmitidos por las enunciaciones jamás están contenidos en una enunciación particular: están determinados en relación con las enunciaciones posibles en ese marco. Lo que quiere decir que esos sentidos son inseparables de la configuración de expectativas de los participantes (1986 [2007]: 203).

5 No es nuestra intención hacer apología del uso de sustancias no legales, pero, a modo de ejemplo, los casos polémicos suelen ser más ilustrativos y esclarecedores.

6 Ello permite explicar, por ejemplo, por qué un enunciado como "portáte bien" adquiere sentidos tan diversos según si es emitido por una jefa a su empleado, una madre a su hijo o un docente a su alumno y, a la vez, resulte, en principio, inaceptable, absurdo o humorístico si lo produce el empleado a su jefa, la hija a su padre o el alumno a su docente. 
Es a partir de estos otros discursos, ya dichos pero actuales en la memoria discursiva, que se leerá, escuchará, interpretará, valorará cualquier nuevo enunciado formulado desde una formación discursiva determinada, proceso de significación que pasa desapercibido al ojo ingenuo debido a la ilusión referencial (Pêcheux, 1975), por lo que sólo puede hacerse evidente a partir del análisis crítico del investigador.

Proponemos pensar estos discursos que circulan al interior de una formación discursiva como un conjunto organizado jerárquicamente, esto es, existiría para cada formación discursiva un discurso dominante, adoptando el concepto de Raiter. Este eje de referencias califica las valoraciones para los signos y expresiones que pueden aparecer en una formación discursiva según una escala que ubica en el polo superior a aquellos que son más prominentes, más fáciles de activar, debido a que son más frecuentes y están más legitimados; mientras que en el polo inferior de la escala estarían aquellos otros sentidos cuya frecuencia de aparición es más baja o prácticamente nula, tienen un grado menor de legitimidad y, en consecuencia, resulta más difícil su activación.

La existencia de un discurso dominante para cada formación discursiva permite explicar, entre otros fenómenos, las supuestas contradicciones que podría evidenciar un individuo que presentara opiniones disímiles sobre un determinado tema al variar la situación de enunciación. Estas oscilaciones no se deberían necesariamente a una personalidad esquizofrénica, sino que responderían a las distintas posiciones de sujeto que implicarían las diferentes situaciones, que movilizan formaciones discursivas específicas y, por consiguiente, discursos dominantes específicos. Difícilmente nos sorprenda (y, de hecho, hasta nos resultaría extraño si ocurriese lo contrario) que los consejos de un padre sobre sexo no sean los mismos que los de un amigo o un médico, aun cuando las personas que desempeñen estos roles en las diferentes situaciones fuera la misma. Suponemos que, en el año 2017, en la sociedad argentina ${ }^{7}$, los signos y valoraciones más legitimados en la posición de padre o de médico están más ligados con la prevención de consecuencias no deseadas de la práctica sexual, mientras que la posición de amigo habilita la circulación de signos y valoraciones más emparentados con el placer y deja en un segundo plano las cuestiones de prevención.

Nuestra propuesta tiene como consecuencia considerar varios discursos dominantes funcionando en una misma sociedad, en lugar de uno sólo para toda la red discursiva. Sin embargo, ello no implica que sus funcionamientos sean independientes unos de otros: las distintas formaciones discursivas establecen entre sí relaciones de fuerza, de jerarquía, de dominancia y subordinación, por lo que sus respectivos discursos dominantes responderán a esas mismas jerarquías. Estas relaciones están sujetas a los condicionamientos sociales propios de un momento histórico determinado, por lo que tanto las formaciones discursivas como sus respectivos discursos dominantes están en constante movimiento. Por otro lado, cabe aclarar que, como ha afirmado Bourdieu (1982), los bienes simbólicos son escasos, lo que nos lleva a plantear que del mismo modo que dos formaciones discursivas pueden compartir signos y valoraciones, también pueden compartir el mismo discurso dominante, es decir, el mismo eje de referencias que califica al conjunto de los discursos que circula en su interior.

De esta manera, son las posiciones de sujeto propias de una formación discursiva determinada las que habilitan la aparición de determinados signos y valoraciones en el texto -independientemente de que estén presentes en la superficie sintagmática- a la vez

7 Creemos que esta suposición puede hacerse extensible a toda la sociedad occidental, pero preferimos remitirnos a la argentina, específicamente a la de Buenos Aires, que es la que mejor conocemos. 
que clausuran o, al menos, obstaculizan la circulación de ciertos otros. Estos signos aparecen ya calificados por su referencia al discurso dominante que funciona al interior de la formación discursiva que domina dicha posición.

Ciertos tipos de chistes explotan este funcionamiento discursivo como un recurso al jugar con la sorpresa sobre lo no dicho, atribuyéndole un sentido inesperado a aquello que había quedado como presupuesto, sobreentendido o implícito. Podemos recordar una entrevista televisiva de hace algunos años a Charly García ${ }^{8}$, cuya adicción a las drogas es de conocimiento público como también lo son sus intentos por rehabilitarse. Allí el músico comentó que nunca había tenido problemas con las drogas. Ante el notable descreimiento del periodista, el artista reiteró que nunca había tenido problemas con las drogas y agregó que siempre las había conseguido.

A riesgo de quedar como antipáticos o aburridos, podemos explicar la gracia del chiste por las diferentes valoraciones sobre el signo [droga] que se ponen en juego según si se enuncia desde la posición de un adicto en rehabilitación, cuya salud ha sido dañada por el consumo; o bien como alguien que hace apología de su uso. En la situación de una entrevista formal, pública, se esperaría, en principio, que no se desafíe el discurso jurídico, que prohíbe el consumo de drogas no recetadas por un médico. Esta expectativa asocia los "problemas" que pueden generar las drogas con las consecuencias que su consumo ocasiona en la salud del paciente. El cambio de posicionamiento -no explicitado- habilita la aparición de otros discursos, más marginales, menos activos, que traen a escena otro universo semántico, fenómeno que rompe el marco de expectativas del interlocutor y, así, produce el efecto de sorpresa y humor.

Más allá de estos ejemplos, consideramos que esta modalidad de funcionamiento resulta aún insuficiente para entender de una forma acabada los procedimientos específicos mediante los cuales la red discursiva regula los sentidos posibles para un enunciado particular, de modo tal que quede integrado bajo los valores del discurso dominante. Por otro lado, tampoco alcanza a explicar cómo es posible cambiar las valoraciones de los signos que circulan en la red o cómo pueden imponerse nuevos signos o tópicos de debate que cuestionen el eje de referencias del discurso dominante imperante.

Precisaremos, entonces, los procedimientos discursivos a partir de los cuales se regulan las interpretaciones posibles de un enunciado particular, procedimientos que incluyen, paralelamente, la exclusión de las interpretaciones no posibles. Consideramos, a su vez, que son estos mismos procedimientos los que permiten la circulación de nuevos signos y valoraciones y que abren, por lo tanto, la puerta a que otras realidades alternativas se impongan y reemplacen a las imperantes.

\section{Apropiación enunciativa}

Tal como hemos venido señalando, el sentido de un texto se presenta como una relación interdiscursiva, en tanto constituye los discursos posibles que el texto habilita. La incorporación de diferentes voces hace aparecer no sólo una pluralidad de puntos de vista sobre un determinado tema, sino también una diversidad de posiciones de sujeto, que atraviesan el texto con mayor o menor preeminencia y traen a escena los signos y valoraciones propios de las memorias discursivas que movilizan, independientemente del grado de explicitud

8 (1951) Músico argentino de gran influencia en el mundo artístico, reconocido no sólo por su talento sino también por su carácter polémico, especialmente en relación con su adicción a las drogas. Para mayor detalle, véase https://es.wikipedia.org/wiki/Charly_García. 
que manifiesten en el texto. Siguiendo la reformulación que hace Guimarães (1998) de la propuesta de Ducrot, pensamos esta confrontación entre los distintos discursos que traen a escena las diferentes posiciones de sujeto como una orientación argumentativa, ya que cada punto de vista incorporado constituiría un argumento a favor de una conclusión determinada, esto es, abriría el camino para la aparición de determinados discursos.

Tal como ha advertido Ducrot (1990), este movimiento que conduce a una conclusión particular y la conclusión misma suelen confundirse, como si en la conclusión estuviera ya contenido el trayecto que conduce a ella o bien en cada punto del trayecto estuvieran ya marcados los pasos que orientan hacia la conclusión. Lejos de considerarlo un razonamiento inválido o una simple omisión de pasos, nosotros atribuimos este desplazamiento a un mecanismo fundamental que opera en el nivel del discurso, que restringe el campo de efectos de sentido posibles: en la medida en que un texto no cuestiona el discurso dominante de la formación discursiva que lo domina, es calificado por el eje de referencias de dicha formación discursiva, que lo asimila y otorga a los signos y expresiones que emplea el texto sus propios valores, "apropiándose" de sus sentidos . El texto queda, así, preso de las categorías ya impuestas por este discurso dominante, que califica sus signos y carga de sentido los silencios que no aparecen en la superficie del texto pero que el interlocutor debe recuperar para su comprensión.

Llamamos a este proceso Apropiación enunciativa y lo definimos como una operación discursiva mediante la cual a un determinado texto se le atribuyen los principios argumentativos - los topoi- que son movilizados por el discurso dominante de la formación discursiva en la que se inscribe el locutor por el hecho de que su texto orienta hacia las mismas conclusiones que este discurso dominante o presenta sus mismos signos y valoraciones, a pesar de que el razonamiento o trayecto argumentativo a partir del cual se fundamenta el encadenamiento no es el mismo.

Esta modalidad de funcionamiento la pudimos apreciar en el análisis que hicimos en un trabajo anterior (Dvoskin, 2015b) sobre la ley de Educación Sexual Integral ${ }^{9}$, sancionada en la Argentina en el año 2006, política que suscitó gran polémica, especialmente en la esfera periodística. Los posicionamientos a favor y en contra de la medida presentaron como trasfondo el enfrentamiento de dos formaciones ideológicas: por un lado, la ciencia, desarrollada por los discursos médico y pedagógico; y, por el otro, la religión, representada principalmente por la Iglesia católica.

En el primer caso, el tema fue abordado como objeto de conocimiento, por lo que el signo [sexualidad] fue valorado a partir del criterio del saber, eje que responde a parámetros de verdad o falsedad. La noción de error permitió establecer conductas "correctas" e "incorrectas" sobre la sexualidad para los adolescentes, por lo que el tema se redujo, desde este paradigma, a las consecuencias no deseadas de su práctica: enfermedades, embarazos no deseados, abusos; todos males que la educación debía prevenir.

La iglesia católica, en cambio, emparentó la sexualidad con la ética y la moral, criterio que le permitió presentar a la familia como la institución privilegiada para inculcar este tipo de educación y, de ese modo, relegar a la escuela a un papel secundario. El signo [sexualidad] quedó asociado con los valores del amor, la responsabilidad, la honestidad y el afecto, que no responden a criterios de verdad y, por lo tanto, no pueden ser evaluados por el discurso pedagógico. La práctica sexual quedó confinada al matrimonio, por lo

9 La Ley Nacional 26.150, denominada "Ley de Educación Sexual Integral”, establece la obligatoriedad de impartir educación sexual en todas las escuelas del país, tanto de gestión estatal como privada, desde el nivel Inicial hasta el Superior de Formación Docente y de Educación Técnica no Universitaria. 
que excluye, en principio, a los adolescentes, razón por la cual el tema resulta irrelevante como contenido curricular o, incluso, de acuerdo con el discurso religioso, contraproducente, debido que el exceso de información podría incentivarlos a realizar prácticas para las que aún no están capacitados.

Más allá de los posicionamientos en relación con la medida, tanto el discurso científico como el religioso presentan el tema de la educación sexual como un problema al valorar el signo [sexualidad] como un peligro o bien como un pecado. A pesar de sus diferencias, ambos discursos ratifican el carácter represivo con que ha sido calificado este signo en las sociedades modernas occidentales (Foucault, 1976; Freud, 1929; Lévi-Strauss, 1949), por lo que quedan integrados bajo los valores de dicho discurso dominante. Dentro de esta red discursiva, todo texto que aborde el tema de la educación sexual como un problema queda atravesado por el discurso dominante de una u otra formación discursiva, por lo que contribuirá a reforzar esta valoración sobre la sexualidad. Aquellas posturas que se manifiesten a favor de la ley por considerar a la educación formal como una vía adecuada para transmitir e inculcar valores sobre sexualidad a los jóvenes, se enmarcarán en una política preventiva, que destaca los aspectos potencialmente peligrosos del sexo. En cambio, aquellos que se pronuncien en contra de la inclusión del tema como contenido curricular, quedarán alineados detrás de un discurso que fomenta su silenciamiento y reproduce, de ese modo, su carácter tabú.

\section{De lo mostrado a lo constitutivo}

Resulta imprescindible, para dar cuenta de la escena discursiva configurada en un texto, comenzar por el análisis de los recursos polifónicos -tales como el discurso referido, la negación, los presupuestos- y observar cuál es la postura que el locutor adopta frente a esta diversidad de voces y cuál es el tipo de relación(es) que mantiene con su(s) destinatario(s).

Estas voces inscriben posiciones de sujeto en el texto, que movilizan las memorias de las formaciones discursivas a las que pertenecen. El análisis de las relaciones de fuerza entre las distintas posiciones de sujeto que atraviesan el texto permite evidenciar el valor de los signos que allí aparecen y reponer qué otros discursos están funcionando de un modo silencioso, ausentes en la superficie, pero actuales en la memoria. En términos de Authier-Revuz (1982), se trata de reconstruir la heterogeneidad constitutiva tomando como punto de partida el análisis de la heterogeneidad mostrada.

Como ya explicitamos anteriormente, coincidimos con Pêcheux (1975) en que el valor de un signo o de una expresión está dado por la formación discursiva en la que se inscribe el individuo como sujeto de enunciación. Ello nos lleva a considerar que la imposición de nuevos valores o de nuevos signos debe estar asociada con un cambio en la formación discursiva. El cuestionamiento del discurso dominante modifica inevitablemente la formación discursiva y el espacio discursivo configurado en relación con un determinado tema, debido a que ciertos signos y valoraciones adquieren mayor preeminencia y otros quedan relegados a un segundo plano, siendo más difícil su activación. De esta manera, un discurso que pretendiera imponer nuevos valores a los signos ya existentes o poner en circulación nuevos signos debe comenzar cuestionando el discurso dominante de la formación discursiva en la que se inscribe. Para ello, debería configurar una nueva relación de fuerzas entre las formaciones discursivas ya existentes, proponer un nuevo ordenamiento entre ellas, de modo tal de que las que ocupan los puestos de mayor prestigio 
e influencia pasen a las posiciones subordinadas, mientras que las que están ubicadas en las posiciones inferiores de la escala pasen a ocupar los puestos dominantes. Esta nueva jerarquización de las formaciones discursivas traería aparejada una nueva calificación de los discursos que circulan en la red, debido a que los signos y valoraciones más difundidos y legitimados serían los de las formaciones discursivas que pasarían a ocupar los puestos más altos de la escala en esta nueva configuración.

Un discurso que cumpliera con estas características sería, siguiendo el cuadro epistemológico de Raiter (2003), un discurso emergente, debido a que inauguraría un nuevo eje de referencias producto de la nueva configuración de fuerzas que establecería entre las diferentes formaciones discursivas. Esto le otorgaría la iniciativa discursiva, dado que todo discurso que pretendiera participar de la cadena discursiva debería hacerlo a partir de los signos y las valoraciones impuestos por este nuevo discurso dominante. Sin embargo, este proceso es lento y complejo, especialmente debido al carácter fundamentalmente inconsciente que regula los mecanismos de significación. De ahí que el análisis crítico sea una herramienta imprescindible.

\section{Conclusiones}

Todo sentido implica un proceso de construcción y una interpretación y es allí donde aparece el trabajo de la ideología. El estudio sobre el sentido se presenta, entonces, como un modo de entender el funcionamiento ideológico del lenguaje. Plantear un sentido único, predeterminado por el emisor, conduce al equívoco de concebir el lenguaje como un reflejo del mundo y de asimilar interacción lingüística con comunicación, todas creencias fuertemente establecidas en el sentido común, que esconden los condicionamientos sociales, políticos y culturales que afectan el uso del lenguaje y que presentan los fracasos (de cognición, comprensión, comunicación) como consecuencia de un déficit del sujeto individual: “O jogo ideológico está na dissimulação dos efeitos de sentido sob a forma de informação, de um sentido único, e na ilusão discursiva dos sujeitos de serem a origem de seus próprios discursos." (Orlandi, [1983] 2011: 32).

Sin embargo, si bien "hablando se entiende la gente", en el sentido común también encontramos expresiones como "no aclares que oscurece"10, que vislumbra el carácter opaco del lenguaje. La ilusión de transparencia, fundamentada en el poder del hablante de controlar la significación de sus enunciados, encuentra en esta frase su contracara, que deja en evidencia que las (buenas) intenciones no son condición suficiente para lograr el efecto deseado, de ahí que un hablante siga una serie de pasos estipulados para generar un determinado sentido no garantiza que su destinatario entienda el mismo sentido ${ }^{11}$.

El sentido no puede ser predeterminado por el sujeto hablante porque su texto significa más allá de las palabras que aparecen efectivamente en la superficie. Es la referencia a la red discursiva lo que otorga valor a los signos y es esta referencia la que repone los vacíos que son necesarios recuperar en todo acto de comprensión. El análisis del sentido

10 Podemos agregar el refrán "no por mucho madrugar amanece más temprano", que también da cuenta de un carácter no lineal entre los motivos que llevan a realizar una acción y los resultados que esa acción podría producir, aunque, en este caso, la relación con el uso del lenguaje no es tan clara.

11 Los llamados "piropos" pueden funcionar como un claro ejemplo de los peligros que conlleva para el analista posicionarse desde el punto de vista de la producción. Si se toma en cuenta exclusivamente el supuesto intento del productor del mensaje de halagar la belleza femenina, no se puede explicar el efecto abusivo y denigratorio que ello puede generar para la destinataria al considerar las condiciones históricas que dan lugar a ese tipo de manifestaciones. 
de un texto constituye un fenómeno de reconocimiento, instancia que involucra factores que exceden lo estrictamente lingüístico y que es necesario considerar si lo que se pretende es identificar y entender por qué circulan determinados signos y sentidos (y no otros). Sólo entendiendo este funcionamiento se podrán buscar caminos alternativos para poner en circulación signos y/o valoraciones diferentes a los de los discursos dominantes, que permitan instaurar nuevas realidades.

La posición del analista resulta de crucial importancia para dar cuenta de estos fenómenos, dado que la crítica exige colocarse en otro lugar. A diferencia de los participantes de la interacción, que procesan los enunciados de manera automática e involuntaria (Raiter, 1999b), el analista explicita sus premisas, pone de manifiesto sus puntos de partida a partir de los cuales realiza el análisis de manera consciente, con el objeto de desnaturalizar aquello que a simple vista se presenta como una verdad evidente, pero que, nada más y nada menos, resulta de un juego de fuerzas y, como tal, es contingente.

\section{Referencias}

ANSCOMBRE, J. C.; DUCROT, O. La argumentación en la lengua. Madrid: Gredos, (1988) 1994.

AUSTIN, J. Cómo hacer cosas con palabras. Buenos Aires: Paidós, 1962.

AUTHIER-REVUZ, J. Heterogeneidad mostrada y heterogeneidad constitutiva: elementos para una aproximación al otro en el discurso. DRLAV, n. 26, París, 1982.

BAJTIN, M. Estética de la creación verbal. México: Siglo XXI, (1982) 2005.

BENVENISTE, E. Problemas de lingüística general. México: Siglo XXI, (1966) 2010. BOURDIEU, P. ¿Qué significa hablar? Economía de los intercambios lingüísticos. España: Akal, (1982) 2001.

DUCROT, O. ¿Qué es el estructuralismo? El Estructuralismo en lingüística. Buenos Aires: Losada, (1968) 1975.

. Polifonía y Argumentación. Cali: Universidad del Valle, 1990.

. El decir y lo dicho. Buenos Aires: Edicial, (1984) 2001.

DVOSKIN, G. Yo sé, Nosotros podemos, Ellos se cuidan. La escena discursiva del debate sobre la Educación Sexual Integral, en Literatura y lingüística. Universidad Católica Silva Henríquez: Santiago, n 30, 2015a, p. 233-256.

. Medios y realidad: formaciones discursivas en disputa. Signo y Seña, Revista del Instituto de Lingüística de la Facultad de Filosofía y Letras, Buenos Aires: Universidad de Buenos Aires, n 27, 2015b, p. 143-169.

FOUCAULT, M. Historia de la sexualidad. La voluntad del saber. Argentina: Siglo XXI, (1976) 2008.

FREUD, S. El malestar en la cultura. Madrid: Amorrortu editores, (1929) 2000.

GARCÍA NEGRONI, M. M.; MONTERO, A. S.; LIEBENSON, M. De la intención del sujeto hablante a la representación polifónica de la enunciación. Acerca de los límites de la noción de intención en la descripción del sentido. Revista de Investigación Lingüística, Universidad de Murcia, n. 16, 2013, p. 237-262.

GRICE, P. Meaning. The Philosophical Review, v. 66, n. 3, 1957, p. 377-388.

GUIMARÃES, E. Interdiscurso, textualidade e argumentacao. Signo y Seña, Revista del Instituto de Lingüística de la Facultad de Filosofía y Letras, Buenos Aires: Universidad de Buenos Aires, 1998. 


\section{Conexão Letras}

JAKOBSON, R. Lingüística y poética. Madrid: Cátedra, (1958) 1988.

KAUFMAN, G. et al. Entre letras III: recursos para el docente. Buenos Aires: Santillana, 2017.

KERBRAT-ORECCHIONI, C. La enunciación de la subjetividad en la lengua. Buenos Aires: Hachette, (1980) 1986.

LAVANDERA, B. El principio de reinterpretación en la teoría de la variación. In: . Variación y significado. Buenos Aires: Hachette, 1984, p. 47-56.

LÉVI-STRAUSS, C. Las estructuras elementales del parentesco. Barcelona: Planeta Agostini, (1949) 1985.

ORLANDI, E. A linguagem e seu funcionamento. As formas do discurso. Campinas:

Pontes Editores, (1983) 2011.

PÊCHEUX, M. El análisis automático del discurso. Madrid: Gredos, (1969) 1978. . Semántica e discurso. Campinas: Editora Unicamp, (1975) 2010.

RAITER, A. Significaciones imposibles. In: RAITER, A. (Comp.). Discurso y ciencia social. Buenos Aires: Eudeba, 1999a, p. 39-50. . Formación discursiva y reproducción ideológica. In: . Lingüística y Política. Buenos Aires: Biblos, 1999b, p. 55-74. . Lenguaje y Sentido Común. Buenos Aires: Biblos, 2003. SAUSSURE, F. Curso de Lingüística General. Buenos Aires: Losada, 2001. SEARLE, J. Actos de habla. Madrid: Cátedra, (1969) 1980.

SIGAL, S.; VERÓN, E. Perón o muerte. Los fundamentos discursivos del fenómeno peronista. Buenos Aires: Hispanomérica, (1985) 2008.

VASALLO, I. Programa Kapelusz. Nuevos desafíos: Lengua y Literatura, Prácticas del lenguaje 3. Buenos Aires: Kapelusz, 2011.

VERÓN, E. La semiosis social. Fragmentos de una teoría de la discursividad. Barcelona: Gedisa, (1986) 2007.

VOLOSHINOV, V. El marxismo y la filosofía del lenguaje. Madrid: Alianza, (1929) 1993.

Recebido em: 05/09/2017 Aceito em: 11/10/2017 